Платонова Я.С.*, Савенкова И.А. Оценка эффективности программы социально-эмоционального и просоциального обучения детей начальной школы

Орловский государственный университет имени И.С. Тургенева, ул. Комсомольская д. 95, Орел, 302026, Россия rupert-green666@yandex.ru*

Статья поступила 16 июня 2020; принята 10 сентября 2020; опубликована 30 сентября 2020

Аннотация. Система российского образования подвергается изменениям: меняются стандарты обучения, перед учениками и учителями ставятся новые задачи и требования, в том числе в период начального образования. От младших школьников ожидают не только знаний по школьным предметам, но и умения сотрудничать, вставать на позицию другого, понимать свои и чужие эмоции, контролировать их, тем самым развивая социально-эмоциональные компетенции детей. Цель статьи являются теоретический анализ проблемы социально-эмоциональных компетенций в современной психологии и эмпирическое исследование эффективности разработанной программы социально-эмоционального обучения как средства развития социально-эмоциональных компетенций у детей начальной школы. Разработанная программа опиралась на такие методы обучения, как решения социальных проблемных ситуаций, ролевых игр, визуальных методов, участия в совместной проектной деятельности, выполнения письменных заданий с просоциальным содержанием, аффективной индукции и моделирования просоциального поведения. Для эмпирической проверки эффективности разработанной программы было организовано исследование с применением авторских методик: 1) тест на эмоциональный словарь; 2) методика изучения просоциального поведения «Номинация сверстников»; 3) методика «Делимся с другими». Результаты исследования показали, что разработанная программа способствует развитию у младших школьников: идентификации эмоций, эмоционального словаря и просоциального поведения. Дальнейшая доработка и совершенствование программы позволит внедрить ее в образовательную практику и тем самым решить задачу о социально-эмоциональном обучении детей.

Ключевые слова: эмоциональный интеллект; социально-эмоциональное обучение; социально-эмоциональные компетенции; просоциальное поведение; младшие школьники.

Информация для цитирования: Платонова Я.С., Савенкова И.А. Оценка эффективности программы социально-эмоционального и просоциального обучения детей начальной школы // Научный результат. Педагогика и психология образования. 2020. Т.6. №3. С. 26-40. DOI: 10.18413/2313-8971-2020-6-3-0-3. 


\title{
Ya.S. Platonova*, $\quad$ Evaluation of the effectiveness of the program for social-emotional I.A. Savenkova and pro-social education of primary school children
}

\author{
Turgenev Oryol State University, \\ 95 Komsomolskaya Str., Orel, 302026, Russia \\ rupert-green666@yandex.ru*
}

Received on June 16, 2020; accepted on September 10, 2020; published on September 30, 2020

\begin{abstract}
Every day, the Russian education system undergoes numerous changes. Teaching standards are changing, new tasks and requirements are being set for students and teachers. Such changes did not bypass the period of primary education. Junior schoolchildren are expected not only to know about school subjects, but also the ability to cooperate, to stand in the position of another, to understand their own and other people's emotions, to control them. In other words, the school should pay attention to the development of the socio-emotional competencies of children. In this regard, a program for social and emotional education of primary school children was developed, based on such methods of training as solving social problems, role-playing, visual methods, participation in joint project activities, fulfilling written tasks with prosocial content, affective induction and modeling of pro-social behavior.To empirically test the effectiveness of the developed program, a study was organized using author's techniques: 1) an emotional dictionary test, the purpose of which is to measure the vocabulary of emotives in junior schoolchildren; 2) methodology for studying prosocial behavior "Peer nomination"; 3) the technique "We share with others," used to study prosocial behavior in younger schoolchildren, as well as the ability to identify emotions. The results obtained made it possible to conclude that the developed program contributes to the development of the following competencies of junior schoolchildren identification of emotions, an emotional dictionary and prosocial behavior. Further refinement and improvement of the program will allow it to be introduced into educational practice and thereby solve the problem of social and emotional education of children.
\end{abstract}

Keywords: emotional intelligence; socio-emotional learning; socio-emotional competencies; prosocial behavior; junior students.

Information for citation: Platonova Ya.S., Savenkova I.A., (2020), "Evaluation of the effectiveness of the program for social-emotional and pro-social education of primary school children", Research Result. Pedagogy and Psychology of Education, 6 (3), 26-40, DOI: 10.18413/2313-8971-2020-6-3-0-3.

Введение (Introduction). В последнее время в обществе популярным стал вопрос о социальных и эмоциональных умениях и навыках, их развитии и влиянии на жизнедеятельность человека. Описывая данные умения, и в научной, и в популярной литературе часто обращаются к таким психологическим феноменам, как эмоциональный интеллект и социально-эмоциональные компетенции.

Вопрос о развитии социальноэмоциональных компетенций и эмоционального интеллекта в целом на сегодняшний день считается одним из самых популярных и часто рассматриваемых (Кузнецова, 2010; Люсин, 2004; Рыжов, 2012; Савен- 
ков, 2006; Bar-On, R. and Parker, J., 2000 и др.). Однако, несмотря на такой интерес к проблеме и существование многочисленных моделей и концепций эмоционального интеллекта, все же остаются неразрешенные вопросы относительно входящих в него социально-эмоциональных компетенций: что к ним в итоге можно отнести? На каких основаниях классифицировать? На чем делать акцент при разработке программ по развитию социально-эмоциональных компетенций как компонента эмоционального интеллекта? Восполнение данных пробелов в теории и решение практической задачи о развитии социально-эмоциональных компетенций делает выбранную тему исследования крайне актуальной.

Основная часть (Main Part). Целью исследования являются теоретический анализ проблемы социально-эмоциональных компетенций в современной психологии и эмпирическое исследование эффективности разработанной программы социальноэмоционального обучения как средства развития социально-эмоциональных компетенций у детей начальной школы.

Эмоциональный интеллект большинство авторов (П. Сэловей, Дж. Мэйер, Д. Гоулман, Р. Бар-Он, Д. Люсин, и др.) определяют как способность человека распознавать, различать и контролировать свои эмоциональные проявления, идентифицировать эмоции и чувства других людей, и использовать эмоциональную информацию для успешного выполнения какой-либо деятельности. В современной литературе такие способности и навыки стали описываться через термин «социально-эмоциональные компетенции» (Апресян, 2019; Найденова, 2014; Савина, Фроловичева, Трухина, 2018).

Социально-эмоциональные компетенции специалисты Национального исследовательского университета «Высшая школа экономики» определяют как навыки, позволяющие человеку устанавливать и поддерживать позитивные социальные контакты, сопереживать и сочувствовать другим людям, осознавать и понимать свои эмоции и чувства, поддерживать позитивный эмоцио- нальный настрой, успешно разрешать конфликты и пр. ${ }^{1}$

Характеристика таких компетенций упирается на существующие модели эмоционального интеллекта.

Самой первой и самой популярной моделью данного феномена была модель, предложенная П. Сэловейем, Д. Мейером и Д. Карузо (Mayer, DiPaolo, Salovey, 1990). Авторы выделили четыре компонента эмоционального интеллекта, лежащие в основе его структуры. Эти компоненты включали в себя ряд способностей, которые, по мнению авторов, осваиваются в онтогенезе последовательно:

1) идентификация эмоций. Включает в себя способности к восприятию эмоций, их распознаванию и адекватному выражению;

2) использование эмоций для повышения эффективности мышления и деятельности. Этот компонент включает способности к использованию эмоций для направления и повышения внимания, а также способность вызывать эмоции, которые способствуют решению различных задач;

3) понимание эмоций. Включает способности к пониманию как своих, так и чужих эмоций, связям между ними, причинам их возникновения;

4) управление эмоциями. Содержит в себе способности контроля и осознания собственных эмоций и эмоциональных состояний других людей.

Не менее популярной стала и модель Д. Гоулмана, основой для которой послужили идеи предыдущих авторов. Гоулман выделил в структуре эмоционального интеллекта две группы навыков: личностные и социальные. Личностные навыки включали в себя самосознание - это осознание собственных эмоций и их анализ, и самоконтроль - способность контролировать разрушительные эмоции и аффекты. Социальные навыки включали социальную чуткость

\footnotetext{
${ }^{1}$ Оценка социальных и эмоциональных навыков в школе: ESP // НИУ «Высшая школа экономики (официальный сайт), $2014 . \quad$ URL: https://ioe.hse.ru/monitoring/esp (дата обращения: 23.11.19).
} 
(эмпатию) и собственно социальные навыки, которые Гоулман определил как умение вести за собой, владение тактикой убеждения и умение разрешать конфликты и разногласия (Гоулман, 2009).

Еще одну модель эмоционального интеллекта предложил клинический психолог и физиолог Рувен Бар-Он (Bar-On, Parker, 2000). В своей модели Бар-Он дает широкую трактовку эмоционального интеллекта. Автор определяет данный феномен как все некогнитивные способности, знания и компетентность, которые дают человеку возможность успешно справляться с различными жизненными ситуациями. Р. Бар-Он выделяет пять сфер компетентности личности, которые можно идентифицировать с компонентами эмоционального интеллекта, каждая из которых состоит из нескольких субкомпонентов:

1) интраперсональные (познание себя): самонаблюдение, эмоциональное самосознание, напористость, самоутверждение, независимость, самоуважение, самоактуализация;

2) интерперсональные (навыки межличностного общения): эмпатия, социальная ответственность, межличностные взаимоотношения;

3) управление стрессом: устойчивость к стрессу, контроль импульсивности;

4) способность к адаптации: связь с реальностью, гибкость, решение проблем;

5) преобладающее настроение: оптимизм, счастье.

В российской науке также было немало предложено моделей эмоционального интеллекта. Пожалуй, самыми крупными из них, по нашему мнению, можно назвать модели А.И. Савенкова и Д.В. Люсина.

А.И. Савенков, рассматривая эмоциональный интеллект как часть социального интеллекта, выделяет в его структуре три группы критериев:

1) когнитивные: социальные знания (знания о людях, понимание других людей), социальная память (память на лица, имена), социальная интуиция (распознавание эмо- ций и чувств), социальное прогнозирование (рефлексия собственного развития);

2) эмоциональные: эмоциональная чувствительность, эмоциональный контроль, сопереживание, степень склонности к психическому заражению, эмпатия, установление эмоциональных связей с другими;

3) поведенческие: социальное восприятие (умение слушать собеседника), социальное взаимодействие (способность и готовность к совместной работе), социальная адаптация (умение объяснять и убеждать других, способность уживаться с другими людьми), способность к саморегуляции (умение регулировать собственные эмоции), способность эффективно работать в условиях стресса (Савенков, 2006).

Д.В. Люсин в структуре эмоционального интеллекта выделяет внутриличностную и межличностную сферы. Внутриличностная сфера, по мнению ученого, характеризуется осознанием собственных эмоций и чувств, пониманием причин возникновения данных эмоций, способностью их идентифицировать и контролировать. Межличностная сфера отличается пониманием эмоций и чувств других людей, умением вызывать «нужные» эмоции у людей и контролировать «нежелательные» (Люсин, 2004).

Таким образом, констатируем, что и в зарубежной, и в российской литературе в качестве компонентов эмоционального интеллекта выделяются как эмоциональные способности, которые включаются преимущественно во внутриличностный интеллект, так и социальные умения и навыки, отражающие эффективность в межличностном взаимодействии. Тем самым, опираясь на понятие компетенций как умений, навыков и способностей человека, можно говорить о социально-эмоциональных компетенциях как составляющих эмоционального интеллекта.

Анализ теоретических источников и научных исследований (Д. Гоулман, Р. БарОн, Д.В. Люсин, Н.Н. Найденова, К.С. Кузнецова и др.) позволил выделить основания для классификации социально-эмоциональных компетенций: 
1. Коммуникативные компетенции: эмпатия, умение вступать и вести диалог, способность точно выражать свои мысли и доносить их партнеру по общению, умение выстраивать положительные социальные отношения.

2. Рефлексивные компетенции: понимание причин появления того или иного эмоционального состояния, осознание собственных эмоций, чувств и последствий их проявления для окружающих.

3. Когнитивные компетенции: идентификация собственных эмоциональных состояний, а также переживаний других людей, владение словарем лексических эмотивов.

4. Поведенческие компетенции: контроль собственного эмоционального состояния, способность использовать полученную эмоциональную информацию в общении с другими людьми и направленность на просоциальное поведение (Ерошенкова, 2019).

Обращение к нормативным документам позволило установить, что сенситивным периодом для развития социальноэмоциональных компетенций в соответствии с Федеральным Государственным образовательным стандартом начального общего образования является младший школьный возраст, поскольку именно в этот период идет активное эмоциональное становление детей, совершенствование их самосознания, возможности к рефлексии и умения встать на позицию партнера, учитывая его потребности и чувства ${ }^{2}$.

Специалисты Национального исследовательского университета «Высшая школа экономики» ${ }^{3}$ выделили три группы социально-эмоциональных навыков, которые, по их мнению, формируются на начальном этапе обучения:1) достижение целей (умение работать над достижением поставленных целей); 2) работа с другими (умение

${ }^{2}$ ФГОС начального общего образования (1-4 кл.), 2009 г. URL:file:///D:/fgos_ru_nach.pdf.pdf (дата обращения: 25.11.19).

${ }^{3}$ Оценка социальных и эмоциональных навыков в школе: ESP // НИУ «Высшая школа экономики (официальный сайт), 2014.URL: https://ioe.hse.ru/monitoring/esp (дата обращения: 23.11.19). строить продуктивные взаимоотношения с другими людьми); 3) управление эмоциями (умение контролировать и понимать проявления как своих эмоций, так и эмоциональных состояний других людей). Исследователи университета подчеркивают, что описанные ими социально-эмоциональные навыки включены в образовательные стандарты начального общего образования. Например, навык «работа с другими» соотносится с таким личностным результатом по ФГОС НОО как толерантность к культуре и истории других народов, уважительное отношение к иным взглядам и мнениям, развитость этических чувств, понимание и сопереживание чувствам других людей, доброжелательность и эмоциональнонравственная отзывчивость ${ }^{4}$.

На официальном сайте Федерального института оценки качества образования также отмечено, что социальноэмоциональные компетенции частично описываются разделами ФГОС и в совокупности представляют собой социальноэмоциональный интеллект ${ }^{5}$. Также в источнике говорится о том, что степень развития социально-эмоциональных компетенций влияет на уровень сформированности коммуникативной компетенции.

Bсе это подчеркивает актуальность проблемы развития социально-эмоциональных компетенций, а также создания программ социально-эмоционального обучения именно для детей младшего школьного возраста. Указанную значимость подчеркивали такие отечественные исследователи, как Д.М. Рыжов, Е.C Шамухаметова, В.В. Пантелеева и И.И. Баранецкий, Е.И. Изотова и др. Полученные ими результаты позволили сделать вывод о том, что развитие социально-эмоциональных компетенций в младшем школьном возрасте про-

\footnotetext{
${ }^{4}$ ФГОС начального общего образования (1-4 кл.), 2009 г. URL:file:///D:/fgos_ru_nach.pdf.pdf (дата обращения: 25.11.19).

5 Социально-эмоциональные компетенции - результат образования в 21 веке // Федеральный институт оценки качества образования (официальный сайт). URL: https://fioco.ru/Contents/Item/Display/2201605 (дата обращения: 25.11.19).
} 
исходит интенсивно, однако характеризуется недостаточной сформированностью отдельных компонентов. Младшие школьники еще плохо ориентируются в выражении собственных эмоций и в понимании эмоциональных состояний других людей. У них еще нет четко сформированного навыка управления собственными эмоциями и чувствами, они плохо ориентируются в эмоциональном мире других людей, т.к. обладают скудным эмоциональным словарем. В связи с этим, обуславливается необходимость создания развивающих программ и программ социально-эмоционального обучения детей младшего школьного возраста (Изотова, 2011; Пантелеева, Баранецкий, 2017; Рыжов, 2012; Шамухаметова, 2015).

Разработкой и реализацией таких программ занимаются многие исследователи (Н.Н. Найденова, К.С. Кузнецова, Р.Г. Апресян и др.), но в анализе теоретической литературы можно заметить, что все они сталкиваются с трудностями эмпирической проверки своих программ, т.к. методики изучения данных компетенций либо не адаптированы, либо вообще отсутствуют (Апресян, 2019; Кузнецова, 2010; Найденова, 2014).

Таким образом, с целью развития у детей младшего школьного возраста социально-эмоциональных компетенций, Е.А. Савиной и ее коллегами была разработана программа социально-эмоционального обучения, основывающаяся на современных представлениях о структурных компонентах эмоционального интеллекта (Савина, 2018).

В основе программы лежат социальные истории, слушая которые младшие школьники вместе с главными героями отправлялись в путешествие по России и знакомились с культурой разных народов. В процессе путешествия герои сталкивались с проблемными ситуациями относительно социального взаимодействия и требующими умения сопереживать, занимать позицию другого человека и применять социальнокультурные знания и умения.

В программе используются следующие методы обучения:
1. Метод решения социальных проблемных ситуаций. Детям предлагается ряд проблемных ситуаций, к которым они должны найти способ решения просоциальной направленности.

2. Метод моделирования. Описание социальных историй содержит в себе образцы просоциальной модели поведения, которая усваивается младшими школьниками при их идентификации с героями историй.

3. Ролевые игры. При их помощи дети отрабатывают навыки просоциального взаимодействия, эмпатии, пропускают через себя эмоциональный опыт героев историй и учатся лучше осознавать свои и чужие эмоциональные состояния.

4. Метод вопросов. Детям предлагалось ответить на ряд вопросов, направленных на осознание собственных эмоциональных состояний, причин их возникновения и последствий, а также на идентификацию эмоций и чувств других людей, что позволяет детям научиться вставать на позицию другого.

5. Визуальные методы. Использование в программе фотографий героев, испытывающих разные эмоциональные состояния, художественных картин, обращенных к различным чувствам, позволяет развить у детей социальную чувствительность, понимание причин возникновения тех или иных эмоций и чувств и повысить способность к идентификации эмоциональных проявлений.

6. Метод аффективной индукции. С помощью описаний поведения, мыслей и чувств главных героев, находящихся в трудных ситуациях, детей побуждают к сочувствию и сопереживанию данным персонажам, пониманию их эмоциональных состояний в той или иной ситуации, что способствует развитию эмпатии.

7. Проектная деятельность, направленная на развитие у детей сотрудничества, умения работать в команде и способности встать на позицию партнера.

8. Выполнение письменных заданий с просоциальным содержанием. От детей требуют написать мини-сочинение на заданную тему или письмо. Наличие просоциальной 
направленности позволяет детям усвоить правила поведения, социальные нормы, сформировать взаимопонимание и уважение к особенностям каждого человека (Савина, 2018).

В своем исследовании мы выполнили эмпирическую проверку эффективности разработанной программы с применением авторских методик.

Согласно гипотезе, реализация данной программы будет способствовать развитию перечисленных социально-эмоциональных компетенций у детей младшего школьного возраста.

Материалы и методы исследования (Materials and research methods). Эмпирическое исследование проводилось с октября 2017 по май 2019 года. Выборку эмпирического исследования составили 92 обучающихся вторых классов начальной школы, среди которых 41 мальчик и 51 девочка. Средний возраст испытуемых -8 лет. Апробация программы социальноэмоционального обучения осуществлялась психологами образовательной организации в двух классах экспериментальной группы (45 человек), еще два класса (47 человек) не подверглись воздействию программы и выступали в качестве контрольной группы. Перед внедрением программы в обеих группах был сделан констатирующий срез с использованием авторских методик с целью выявления особенностей развития социально-эмоциональных компетенций у детей начальных классов. После чего в обучающую программу школьников экспериментальной группы вводились уроки социально-эмоционального обучения. Для чистоты эксперимента и контроля эффекта ожидания экспериментатора использовался двойной слепой метод: 1) диагностику проводили ассистенты, не вовлеченные в апробацию самой программы; 2) ассистенты не знали, какой класс выступает в качестве контрольной, а какой в качестве экспериментальной групп.

После реализации программы в двух группах (экспериментальной и контроль- ной) был сделан контрольный срез с применением тех же авторских методик.

При проведении исследования были использованы методики, разработанные профессором Е.А. Савиной:

1) тест на эмоциональный словарь, цель которого измерение у младших школьников словарного запаса эмотивов, т.е. слов, обозначающих эмоции;

2) методика изучения просоциального поведения «Номинация сверстников»;

3) методика «Делимся с другими», применяемая с целью изучения у младших школьников просоциального поведения, а также способности к идентификации эмоций и эмпатии (Савина, 2018).

Исследование проводилось индивидуально с каждым ребенком. Все ответы испытуемых фиксировались дословно в протоколах.

Тест на эмоциональный словарь использовался для измерения у младших школьников словарного запаса эмотивов, т.е. слов, обозначающих эмоции. При проведении данной методики младшим школьникам предлагались шесть сценариев, в которых описывались эмоциогенные ситуации. Детям давалась следующая инструкция: «Я прочитаю тебе несколько историй и спрошу тебя о том, как герои истории чувствуют себя». Далее по очереди зачитывались шесть различных ситуаций, в конце которых испытуемому задавались вопросы: «Что чувствует герой?» и «Какое еще чувство он может испытывать?». Ответы дословно фиксировались в протоколе.

Для изучения просоциального поведения использовалась методика «Номинация сверстников». Детей просили номинировать одноклассников на следующие категории: помогает другим со школьными заданиями, делится с другими, проявляет сострадание и приглашает играть. Необходимо было убедиться, что ребенок понимает, что ему нужно назвать сверстника или сверстников из своего класса. Ребенок мог назвать одного, нескольких детей или не назвать вообще никого. Никаких указаний на этот счет давать нельзя. На каждого ребенка подсчиты- 
вались его номинации по каждой из ситуаций и заносились в таблицу.

Методика «Делимся с другими» проводилась с целью изучения у младших школьников просоциального поведения, а также способности к идентификации эмоций и эмпатии. Стимульный материал представлен в виде трех конвертов с фотографиями детей, испытывающих негативные эмоции и набором из 15 наклеек. Ребенку демонстрировалась фотография и зачитывалась история. Затем задавался вопрос о том, что чувствует герой истории. После этого ребенку давалось пять наклеек и зачитывалась инструкция: «Вот пять наклеек. Ты можешь их все оставить себе или ты можешь поделиться ими с ... (имя героя истории), чтобы он себя лучше чувствовал. Хочешь поделиться?». Количество отданных наклеек фиксировалось в протоколе.

Научные результаты и дискуссия (Research Results and Discussion). Ответы испытуемых обрабатывались методом контент-анализа. В дальнейшей обработке результатов применялись следующие матема- тико-статистические методы: нахождение среднего арифметического значения и дисперсионный анализ с повторным измерением (ANOVA).

В ходе контрольного этапа эмпирического исследования экспериментальной и контрольной групп, проводимого после внедрения программы социальноэмоционального обучения, были получены следующие результаты.

Дети экспериментальной группы после обучения обладали достаточно обширным эмоциональным словарем (от 3 до 11 эмотивов, в среднем 7 эмотивов), состоящим не только из привычных и знакомых детям эмоций и чувств, но и из сложных, вторичных эмоциональных состояний. У некоторых детей при описании эмоций присутствовала их замена на экспрессивные действия и поведенческие реакции, которые соответствуют тем или иным эмоциональным состояниям. Также у небольшого процента детей было замечено видоизменение лексических эмотивов в слова, которых нет в русском языке (рис. 1).

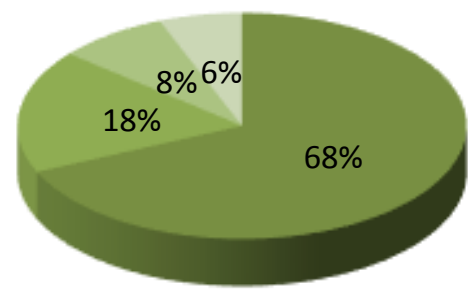

- Смогли идентифицировать
Замена на экспрессивные реакции

Рис.1 Процентное распределение ответов детей по методике «Эмоциональный словарь»

Fig.1 Percentage distribution of children's responses according to the Emotional Dictionary Methodology
Почти все дети без труда смогли идентифицировать базовые эмоции (радость, грусть, печаль и страх), вербализировать их, показывая понимание их содержания и сущности. Также некоторые дети демон- стрировали узнавание более сложных эмоциональных состояний.

Просоциальное поведение детей экспериментальной группы выражалось в большей степени, в том, что они делятся 
различными значимыми для них самих предметами со своими сверстниками, и, в меньшей степени, в том, что они проявляют активность по отношению к тем детям, которые не вовлечены в различные развлека- тельные мероприятия, организованные их сверстниками, т.е. их просоциальное поведение направленно преимущественно на материальную поддержку и помощь другому человеку (рис. 2).

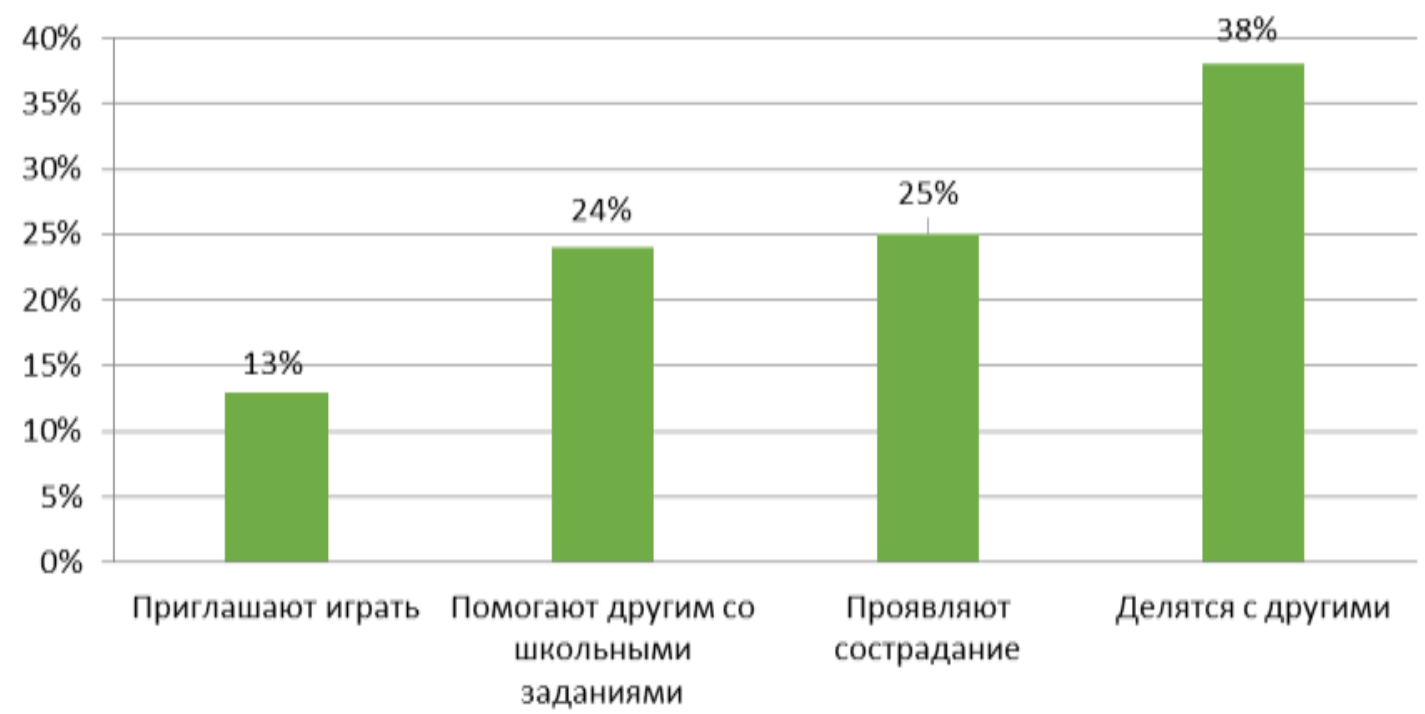

Рис. 2. Процентное распределение номинаций детей экспериментальной группы Fig. 2 Percentage distribution of nominations for children in the experimental group

У детей экспериментальной группы были замечены проявления когнитивного, эмоционального и поведенческого уровня эмпатии. Проявление эмпатии в большей степени фиксировалось у девочек, нежели у мальчиков данного возраста. Однако и девочки, и мальчики в равной степени проявляют эмпатию к представителям своего и противоположного пола, а также к людям другой национальной принадлежности.

Анализ особенностей социальноэмоциональных компетенций у детей контрольной группы показал, что эмоциональный словарь детей этой группы имеет ограниченный объем лексических эмотивов: от 1 до 6 эмотивов, в среднем 3 словаэмотива. При назывании эмоциональных состояний имела место детская этимология, которая, как мы предположили, объясняется особенностями данного возраста и не влияет на уровень развития социальноэмоциональных компетенций, если при этом измененный эмотив адекватен эмоциоген- ной ситуации. У некоторых детей присутствовала замена названий эмоциональных состояний экспрессивными действиями и поведенческими реакциями, которые сопровождают ту или иную эмоцию. Обнаружены трудности с определением дихотомий эмоций, которые были характерны только для детей контрольной группы. Например, чтобы образовать эквивалент эмоции грусти или печали, дети добавляли приставку «не» к слову радость. Встречались также такие слова как «неиспуг» и «невеселье». Также дети могли употреблять эмотивы, неадекватные эмоциогенной ситуации (например, в ситуации проявления страха дети называли эмоцию радости). Можно предположить, что активный словарный запас таких детей содержит эмотивы, однако дети не знают или не до конца понимают значения тех или иных эмоций и чувств, их проявлений, а также при каких эмоциогенных обстоятельствах они возникают (рис. 3). 


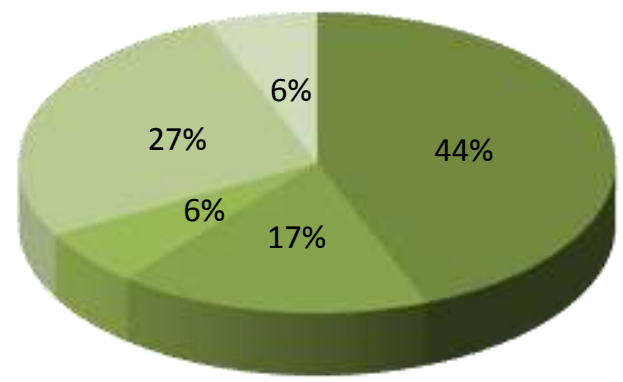

\author{
- Смогли идентифицировать \\ Присутствовала этимология \\ Замена на экспрессивные реакции \\ Не смогли идентифицировать \\ Образование противоположного полюса эмоции при помощи приставки "не"
}

Рис. 3. Процентное распределение ответов детей контрольной группы по методике «Эмоциональный словарь»

Fig. 3. Percentage distribution of children's responses in the control group according to the Emotional Dictionary Methodology

Способность к идентификации эмоциональных состояний детей контрольной группы лучше проявлялась в отношении таких эмоций и чувств, как радость, грусть, обида, страх и испуг. В меньшей степени горя и восторга. Правильно идентифицировать и вербализовать эмоцию к зачитываемым ситуациям получилось у чуть меньшей половины детей. Наиболее успешно дети справились с идентификацией эмоций по фотографиям героев. Остальные же испытывали следующие трудности:

- дети понимали, что герою «хорошо» или «плохо», но вербализовать эмоциональное состояние не могли;

- дети называли определенную эмоцию, однако названная эмоция не соответствовала эмоциогенной ситуации, что говорит о непонимании детьми содержания имеющихся у них эмотивов;
- второклассники не смогли идентифицировать эмоциональное состояние героя истории ни по описанию ситуации, ни по демонстрации фотографии и давали ответы, не имеющие отношения к эмоциям героя или отвечали, что не знают.

Просоциальное поведение детей контрольной группы так же, как и экспериментальной, в большей степени проявлялось в материальной помощи своим товарищам: они делятся карандашами, если у другого их нет, учебниками, угощают конфетами и т.д. В меньшей степени просоциальное поведение детей направлено на вовлечение в совместное взаимодействие тех детей, которые сами не проявляют инициативы или по каким-то причинам отвергаются сверстниками (рис. 4). 


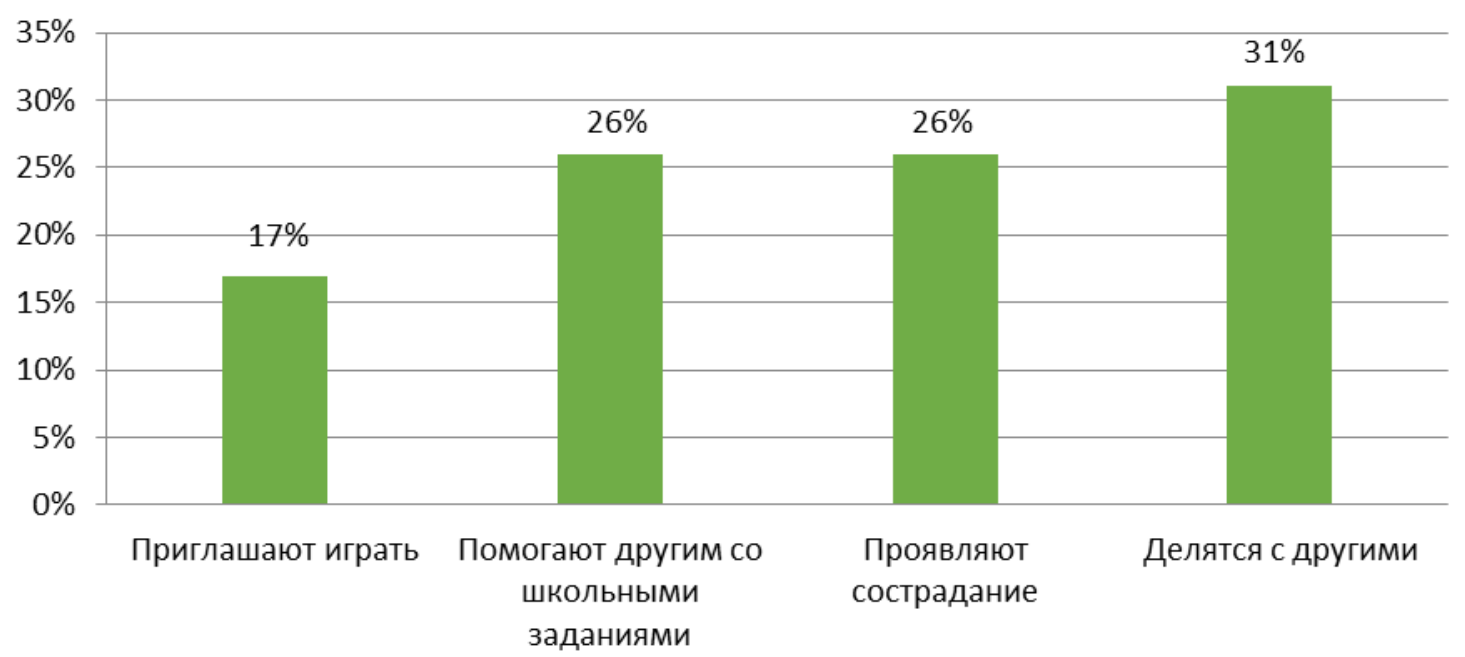

Рис. 4. Процентное распределение номинаций детей контрольной группы

Fig. 4. Percentage distribution of children's nominations in the control group

Обнаружено проявление всех трех уровней эмпатии: когнитивный уровень (понимали, что испытывает герой истории и называли его) эмоциональный уровень (проявляли сочувствие и сопереживание к состояниям героев) и поведенческий уровень эмпатии (предпринимали попытки утешить и улучшить состояния героев, делились с ними наклейками, предлагали дру- гие варианты выхода из сложной ситуации). К представителям своего и противоположного пола, а также к ребенку другой национальности эмпатия детей контрольной группы проявлялась в равной степени.

Сравнительные показатели по методике «Номинация сверстников» испытуемых экспериментальной и контрольной групп представлены в табл. 1.

Таблица 1

Средние значения и стандартные отклонения по методике «Номинация сверстников» Table 1

Average values and standard deviations according to the Peer "Nomination Methodology"

\begin{tabular}{|c|c|c|c|c|c|c|c|c|c|c|c|}
\hline \multicolumn{6}{|c|}{ Экспериментальная группа } & \multicolumn{6}{|c|}{ Контрольная группа } \\
\hline \multicolumn{2}{|c|}{ До обучения } & \multicolumn{2}{|c|}{$\begin{array}{c}\text { После } \\
\text { обучения }\end{array}$} & $\mathrm{F}$ & $\mathrm{p}$ & \multicolumn{2}{|c|}{ До обучения } & \multicolumn{2}{|c|}{$\begin{array}{c}\text { После } \\
\text { обучения }\end{array}$} & $\mathrm{F}$ & $\mathrm{p}$ \\
\hline M & SD & M & $\mathrm{SD}$ & \multirow{2}{*}{4,164} & \multirow{2}{*}{0,047} & M & SD & M & SD & \multirow{2}{*}{0,01} & \multirow{2}{*}{0,921} \\
\hline 2,69 & 2,58 & 3,6 & 3,65 & & & 3,42 & 3,44 & 3,57 & 4,18 & & \\
\hline
\end{tabular}

M - среднее значение;

$\mathrm{SD}$ - стандартное отклонение

Дисперсионный анализ с повторным измерением показал, что дети в экспериментальной группе номинировали больше сверстников, демонстрирующих просоциальное поведение, $\mathrm{F}=4,164, \mathrm{p}=0,047$. В контрольной группе изменение было статистически не значимо, $\mathrm{F}=0,01, \mathrm{p}=0,921$. Интересно, что независимо от серии экспе- римента и группы, девочки номинировали больше просоциально ориентированных сверстников, чем мальчики.

Сравнительные показатели по методике «Эмоциональный словарь» испытуемых экспериментальной и контрольной групп представлены в табл. 2. 
Таблица 2

Средние значения и стандартные отклонения по методике «Эмоциональный словарь»

Average values and standard deviations according to the "Emotional Dictionary Methodology"

\begin{tabular}{|c|c|c|c|c|c|c|c|c|c|c|c|}
\hline \multicolumn{6}{|c|}{ Экспериментальная группа } & \multicolumn{6}{|c|}{ Контрольная группа } \\
\hline \multicolumn{2}{|c|}{$\begin{array}{c}\text { до } \\
\text { обучения }\end{array}$} & \multicolumn{2}{|c|}{$\begin{array}{c}\text { после } \\
\text { обучения }\end{array}$} & \multirow{3}{*}{$\begin{array}{c}\mathrm{F} \\
8,016\end{array}$} & \multirow{2}{*}{$\begin{array}{c}\mathrm{p} \\
0,007\end{array}$} & \multicolumn{2}{|c|}{$\begin{array}{c}\text { до } \\
\text { обучения }\end{array}$} & \multicolumn{2}{|c|}{$\begin{array}{c}\text { после } \\
\text { обучения }\end{array}$} & $\mathrm{F}$ & $\mathrm{p}$ \\
\hline M & $\mathrm{SD}$ & M & SD & & & M & $\mathrm{SD}$ & M & $\mathrm{SD}$ & & \\
\hline 5,38 & 1,77 & 6,40 & 1,73 & & & 6,02 & 1,75 & 6,36 & 1,50 & & \\
\hline
\end{tabular}

M - среднее значение;

$\mathrm{SD}$ - стандартное отклонение

Дети экспериментальной группы также показали улучшение эмоционального словаpя, $F=8,016, p=0,007$, а в контрольной группе никаких изменений не произошло, $\mathrm{F}=1,92$, $\mathrm{p}=0,173$. Половых различий по эмоциональ- ному словарю получено не было.

Сравнительные показатели по методике «Делимся с другими» испытуемых экспериментальной и контрольной групп представлены в табл. 3.

Таблица 3

\section{Средние значения и стандартные отклонения по методике} «Делимся с другими»

Table 3

\section{Average values and standard deviations according to the method "We share with others"}

\begin{tabular}{|c|c|c|c|c|c|c|c|c|c|c|c|}
\hline \multicolumn{6}{|c|}{ Экспериментальная группа } & \multicolumn{6}{|c|}{ Контрольная группа } \\
\hline \multicolumn{2}{|c|}{$\begin{array}{c}\text { До обуче- } \\
\text { ния }\end{array}$} & \multicolumn{2}{|c|}{$\begin{array}{c}\text { После обу- } \\
\text { чения }\end{array}$} & $\mathrm{F}$ & $\mathrm{p}$ & \multicolumn{2}{|c|}{$\begin{array}{c}\text { До обуче- } \\
\text { ния }\end{array}$} & \multicolumn{2}{|c|}{$\begin{array}{c}\text { После обу- } \\
\text { чения }\end{array}$} & $\mathrm{F}$ & $\mathrm{p}$ \\
\hline M & $\mathrm{SD}$ & M & SD & \multirow{2}{*}{1,734} & \multirow{2}{*}{0,306} & M & SD & M & SD & \multirow{2}{*}{1,26} & \multirow{2}{*}{0,268} \\
\hline 8,66 & 3,7 & 8,95 & 4,1 & & & 9,08 & 2,94 & 9,8 & 3,54 & & \\
\hline
\end{tabular}

М - среднее значение;

$\mathrm{SD}$ - стандартное отклонение

В результате дисперсионного анализа с повторным измерением было обнаружено, что реализованная программа практически не повлияла на желание детей делиться с другими с целью улучшения состояния другого, $\mathrm{F}=1,734, \mathrm{p}=0,306$. В контрольной группе никаких изменений также не произошло, $\mathrm{F}=1,26, \mathrm{p}=0,268$. Существует несколько объяснений таким результатам. Вопервых, возможно, что в программе делает- ся недостаточный акцент на то, что нужно делиться с другими, проявляя сочувствие и сострадание. Второе объяснение связано с тем, что и до обучения дети в экспериментальной и в контрольной группе показали высокие результаты по методике «Делимся с другими» - в среднем, они поделились 10 наклейками из 15. Наконец, сами наклейки, использованные для этой методики, могли 
не представлять для детей большой ценности, поэтому дети легко ими делились.

В целом, сравнение средних значений по методикам «Номинация сверстников» и «Эмоциональный словарь» показывает, что показатели по таким компонентам эмоционального интеллекта как просоциальное поведение и словарь лексических эмотивов в экспериментальной группе после развивающего воздействия значимо увеличились.

Анализ развивающего эффекта программы позволил выявить следующие изменения в развитии социально-эмоциональных компетенций:

1. Зафиксированы изменения в сторону повышения уровня эмоционального словаря экспериментальной группы: увеличился объем запаса лексических эмотивов - дети могли назвать от 3-х до 11 различных эмоций и чувств; при назывании эмоций младшие школьники пользовались всем спектром эмоциональных проявлений, учитывая возрастающую интенсивность чувства: от радости до восторга, от злости до гнева, от грусти до горя и т.д.; называемые эмоциональные состояния были адекватны и соответствовали эмоциогенной ситуации, что говорит о понимании детьми эмотивов, которыми они владеют.

2. Дети в экспериментальной группе номинировали больше сверстников, демонстрирующих просоциальное поведение, т.е. под воздействием обучающего эффекта программы произошло изменение поведения младших школьников в сторону просоциальной направленности. Качественный анализ показал, что чаще всего просоциальное поведение проявляется в материальной помощи другому. Были выявлены также гендерные различия: независимо от серии эксперимента и группы, девочки номинировали больше просоциально ориентированных сверстников, чем мальчики, что может говорить о том, что девочки более чувствительны к проявлению просоциального поведения, они больше замечают и запоминают сочувствие, сопереживание и отзывчивость со стороны других людей.
3. Было выявлено совершенствование способности к идентификации эмоциональных состояний: дети не просто воспринимали экспрессивные признаки проявления той или иной эмоции, но и понимали ее содержание и могли вербализировать при помощи эмотивов; повысилась способность к идентификации таких базовых эмоций как радость, грусть, печаль и страх - практически все дети без труда идентифицировали и называли данные эмоции.

Таким образом, мы можем говорить, что разработанная программа, основанная на таких методах обучения, как решения социальных проблемных ситуаций, ролевых игр, визуальных методов, участия в совместной проектной деятельности, выполнения письменных заданий с просоциальным содержанием, аффективной индукции и моделирования просоциального поведения, способствует развитию социальноэмоциональных компетенций (идентификации эмоций, эмоционального словаря и просоциального поведения) у детей младшего школьного возраста.

Заключение (Conclusions). Подводя итог, можно сказать, что в данном исследовании проведен теоретический анализ проблемы эмоционального интеллекта и социально-эмоциональных компетенций, описаны особенности их развития у младших школьников, осуществлена эмпирическая проверка эффективности разработанной программы социально-эмоционального обучения как средства развития социальноэмоциональных компетенций детей начальной школы, которая в дальнейшем может быть внедрена в образовательную практику.

Проведенное исследование показывает, что разработанная программа социальноэмоционального обучения, основанная на социальных историях с просоциальным содержанием, способствует развитию социально-эмоциональных компетенций младших школьников. Мы также выяснили, что использование в программах социальноэмоционального обучения таких обучающих методов, как решение социальных проблемных ситуаций, ролевые игры, визуальные 
методы, участие в совместной проектной деятельности, выполнение письменных заданий с просоциальным содержанием, аффективная индукция и моделирование просоциального поведения будет также способствовать развитию и совершенствованию социально-эмоциональных компетенций младших школьников и их эмоционального интеллекта в целом.

Перед нами стоят задачи по дальнейшему совершенствованию и модернизации программы, доработке методик, которые позволят более точно измерить уровни развития социально-эмоциональных компетенций. Решение данных задач позволит внедрить программу социально-эмоционального обучения в образовательную практику и тем самым повысит социально-эмоциональные компетенции детей.

\section{Список литературы}

Апресян Р.Г. Концепция социальноэмоционального обучения и задачи морального воспитания // Вопросы психологии. 2019. №1. C. 29-39.

Гоулман Д. Эмоциональный интеллект [пер. с англ. А.П. Исаевой]. М.: АСТ МОСКВА, 2009. $478 \mathrm{c}$.

Ерошенкова Е.И. Просоциальная направленность педагогической деятельности в современной науке и образовании: от сущности к содержанию // Научный результат. Педагогика и психология образования. 2019. Т.5, №2. С. 3-16. DOI: 10.18413/2313-8971-2019-5-2-0-1

Изотова Е.И. Когнитивные и поведенческие репрезентации эмпатии в дошкольном и младшем школьном возрасте // Психологические исследования: электронный научный журнал, 2011. №5(19). URL: http://psystudy.ru (дата обращения: 20.11.19).

Кузнецова К.С. К вопросу о формировании эмоционального интеллекта// Ученые записки. Сер. Психология. Педагогика. 2010. Т.3. №4(12). С. 84-93.

Люсин Д.В. Современные представления об эмоциональном интеллекте // Социальный интеллект: теория, измерение, исследования / под ред. Д.В. Люсина, Д.В. Ушакова. М.: ИП PAH, 2004. С. 29-36.

Найденова Н.Н. Компетенции и социально-эмоционального развитие // Образование через всю жизнь: непрерывное образование в ин- тересах устойчивого развития. 2014. Т. 12. №1. C. 159-156.

Пантелеева В.В., Баранецкий И.И. Развитие эмпатии младших школьников средствами духовно-нравственного воспитания // Вектор науки ТГУ. Сер. Педагогика, психология. 2017. №4(31). С. 74-79.

Рыжов Д.М. Современные представления об эмоциональном интеллекте // Вестник ЧПГУ им. И.Я. Яковлева. 2012. №1 (73). Ч.2. С. 142-147.

Савенков А.И. Эмоциональный и социальный интеллект как предикторы жизненного успеха // Вестник практической психологии образования. 2006. №1(6). С. 30-38.

Савина Е.А., Фроловичева Т.Ю., Трухина А.А. Разработка и пилотирование программы социально-эмоционального обучения для детей начальной школы «Широка страна моя родная: Путешествие по России» // Перспективы Науки и Образования. 2018. №1(31). С. 98-106.

Шамухаметова Е.С. Особенности межличностного эмпатического взаимодействия младших школьников // Вестник КГУим. Н.А. Некрасова. 2015. Т.21. №1. С. 75 - 77.

Bar-On, R. and Parker, J. (2000), "Emotional and social intelligence: Insights from the Emotional Quotient Inventory", Handbook of emotional intelligence, Jossey-Bass, San Francisco, State of California, USA, 363-388.

Mayer, J.D., DiPaolo M. and Salovey P. (1990), "Perceiving affective content in ambiguous visual stimuli: A component of emotional intelligence", Journal of Personality Assessment, 54, 772-781.

\section{References}

Apresyan, R.G. (2019), "The Concept of Social and Emotional Learning and the Tasks of Moral Education", Voprosy psikhologii, 1, 29-39. (In Russian).

Goleman, D. (2009), Emotsionalny intellect [Emotional Intelligence], Translated by Isaeva A.P., AST, Moscow, Russia.

Eroshenkova, E.I., (2019) "Prosocial orientation of pedagogical activity in modern science and education: from essence to content", Research Result. Pedagogy and Psychology of Education, 5 (2), 3-16, DOI: 10.18413/2313-8971-2019-5-2-0-1. (In Russian).

Izotova, E.I. (2011), "Cognitive and Behavioral Representations of Empathy in Preschool and Junior School Age", Psychological Research, 5 (19) [Online], available at: http://psystudy.ru (Accessed 20 November 2019). (In Russian). 
Kuznetsova, K.S. (2010), "On the issue of the formation of emotional intelligence", Uchenyezapiski. Ser. Psikhologiya. Pedagogika, 4 (12), 84-93. (In Russian).

Lyusin, D.V. (2004), "Modern ideas about emotional intelligence", in Ushakov D.V. (ed.), Sotsialnyintellekt: teoriya, izmerenie, issledovaniya [Social intelligence: theory, measurement, research],IP RAS, Moscow, Russia, 29-36.

Naidyonova, N.N. (2014), "Competencies and socio-emotional development", Obrazovanie cherez vsyu zhizn: nepreryvnoe obrazovanie $v$ interesah ustojchivogo razvitiya, 12 (1), 159-156. (In Russian).

Panteleeva, V.V. and Baranetsky I.I. (2017), "Development of empathy for junior schoolchildren by means of spiritual and moral education", Vektornauki TGU. Ser. Pedagogika, psixologiya, 4 (31), 74-79. (In Russian).

Ryzhov, D.M. (2012), "Modern ideas about emotional intelligence", Vestnik of the State Pedagogical University named after I.Ya. Yakovlev, 1 (73), 142-147. (In Russian).

Savenkov, A.I. (2006), "Emotional and social intelligence as predictors of life success", Vestnik prakticheskoj psikhologii i obrazovaniya, 1 (6), 3038. (In Russian).

Savina, E.A., Frolovicheva, T.Yu. and Trukhina, A.A. (2018), "The development and piloting of a program of social and emotional education for children of an elementary school "My home country is wide: Traveling in Russia", Perspectives on Science and Education, 1, 98-106. (In Russian).

Shamukhametova, E.S. (2015), "Features of interpersonal empathic interaction of younger schoolchildren", Vestnik KGU im. N.A. Nekrasova, 21 (1), 75-77. (In Russian).
Bar-On, R. and Parker, J. (2000), "Emotional and social intelligence: Insights from the Emotional Quotient Inventory", Handbook of emotional intelligence, Jossey-Bass, San Francisco, State of California, USA, 363-388.

Mayer, J.D, DiPaolo, M, and Salovey P. (1990), "Perceiving affective content in ambiguous visual stimuli: A component of emotional intelligence", Journal of Personality Assessment, (54), 772-781.

Информация о конфликте интересов: авторы не имеют конфликта интересов для декларации. Conflicts of Interest: the authors have no conflict of interest to declare.

\section{Данные авторов:}

Платонова Яна Степановна, магистрант 1 курса института педагогики и психологии, Орловский государственный университет им. И.С. Тургенева. ORCID: 0000-0002-4641-7667.

Савенкова Ирина Анатольевна, кандидат психологических наук, доцент, заведующая кафедрой общей и возрастной психологии, Орловский государственный университет им. И.С. Тургенева.

\footnotetext{
About the authors:

Yana S. Platonova, 1st year Master's Degree Student, Institute of Pedagogy and Psychology, Turgenev Oryol State University. ORCID: 0000-00024641-7667.
}

Irina A. Savenkova, Candidate of Psychological Sciences, Associate Professor, Head of the Department of General and Age Psychology, Turgenev Oryol State University. 